\title{
Structural and Electronic Parameters of Complex Niobates and Tantalates
}

\author{
V. V. Atuchin, S. V. Borisov, N. V. Pervukhina, and Zhaoming Zhang
}

\begin{abstract}
Structural properties of anhydrous $\mathrm{Nb}^{5+}$-niobates and $\mathrm{Ta}^{5+}$-tantalates have been evaluated with the help of classic polyhedra approach and atomic net model. $X$-ray photoelectron spectroscopy (XPS) is utilized as a powerful method to determine the binding energy (BE) of individual atoms in the crystal lattice. Chemical bonding effects are discussed for niobates and tantalates using the binding energy differences $\Delta_{\mathrm{Nb}}$ $=\left(B E O 1 s-B E ~ N b 3 d_{5 / 2}\right)$ and $\Delta_{T a}=\left(B E O 1 s-B E T a 4 f_{7 / 2}\right)$ as key parameters to relate structural and electronic properties of the compounds with pronounced dielectric nature. Photocatalytic materials such as $\mathrm{Sr}_{2} \mathrm{Nb}_{2} \mathrm{O}_{7}, \mathrm{Ta}_{2} \mathrm{O}_{5}, \mathrm{LiTaO}_{3}$, and $\mathrm{Sr}_{2} \mathrm{Ta}_{2} \mathrm{O}_{7}$ are considered in particular.
\end{abstract}

Index Terms-niobate; tantalate; atomic net; XPS; chemical bonding.

\section{INTRODUCTION}

Complex oxide compounds containing niobium and tantalum play a very important role in many areas of microand nanoelectronics, nanochemistry and materials science [1-7]. Because of the wide structural geometries with strong distortion of the $\mathrm{MO}_{6}(\mathrm{M}=\mathrm{Nb}$, Ta) octahedra and high electronic polarizability of the $\mathrm{M}-\mathrm{O}$ bonds, niobates and tantalates show versatile electronic and optical properties and pronounced ability for the formation of noncentrosymmetrical crystal structures [8-11]. In oxides the $\mathrm{M}^{5+}$ ions are coordinated by four or six oxygen atoms. To illustrate these coordinations, crystal structure of $\mathrm{LaNbO}_{4}$, in space group $I 2 / a$, and $\mathrm{LiNbO}_{3}$, in space group $R 3 c$, are shown in Figures 1 and 2, respectively [12,13]. Many niobate and tantalate crystals show high ferroelectric, piezoelectric and nonlinear optical properties [8,9]. In technological applications, niobate crystals are used in the fabrication of nonlinear optical and integrated optical devices, acousto-electronic devices, photocatalysts and nanotechnology [3-7,14-18]. The niobates and tantalates in which niobium and tantalum are in the highest formal oxidation state $\mathrm{M}^{5+}$ are wide gap dielectrics transparent in visible and near-IR ranges. It is worthwhile noting that

Manuscript received May 15, 2011; revised June 17, 2011.

V. V. Atuchin is with the Laboratory of Optical Materials and Structures, Institute of Semiconductor Physics, SB RAS, Novosibirsk, 630090, Russia (e-mail: atuchin@thermo.isp.nsc.ru).

S. V. Borisov is with the Laboratory of Crystal Chemistry, Institute of Inorganic Chemistry, SB RAS, Novosibirsk, 630090, Russia (e-mail: borisov@niic.nsc.ru).

N. V. Pervukhina is with the Laboratory of Crystal Chemistry, Institute of Inorganic Chemistry, SB RAS, Novosibirsk, 630090, Russia (e-mail: pervukh@niic.nsc.ru).

Zhaoming Zhang is with the Australian Nuclear Science and Technology Organisation, Locked Bag 2001, Kirrawee DC, NSW 2232, Australia (e-mail: zzx@ansto.gov.au). surface reduction of $\mathrm{M}^{5+}$-oxide crystals to lower the valence states of $\mathrm{M}$ cations can be achieved by ion or electron bombardment widely used in modern electronic technology for surface treatments [4,19-21]. Chemical state of the crystal surface can be modified by the formation of the solid solutions that results in strong variation of chemical reactivity and physical properties [1,2,4,7,14,17,20-23]. So, the bulk and surface properties of niobate and tantalate crystals are strictly dependent on the $\mathrm{M}$ ion chemical state, which should be controlled with high reliability.

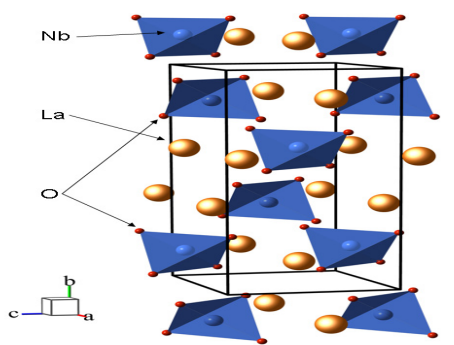

Fig. 1. Crystal structure of $\mathrm{LaNbO}_{4}$. Unit cell is outlined. $\mathrm{Nb}$ and $\mathrm{O}$ lone atoms are omitted for clarity.

When the oxide crystal lattice formation takes place due to valence electron exchange between metals and oxygen and atomic ordering to achieve minimum crystal energy, two effects interesting for our current study are proceeding in parallel. On the one hand, atomic ordering results in a suite of interatomic distances that is a principal characteristic of selected oxide crystal, for example, a set of $\mathrm{Nb}-\mathrm{O}$ distances in a niobate. Futhermore, when metal interacts with oxygen, great redistribution of electronic density occurs as a shift of valence electrons from metal atom to oxygen resulting in

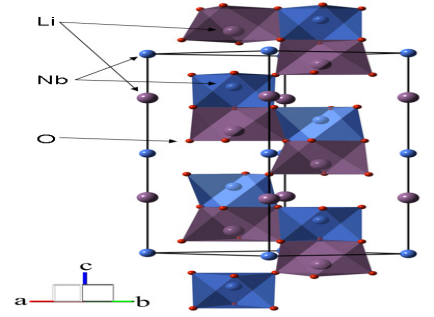

Fig. 2. Crystal structure of $\mathrm{LiNbO}_{3}$. Unit cell is outlined.

significant variations of electronic structure of inner shells of cation and anion. The effective displacement of valence electron density away from the atomic nucleus results in the reduction of electrical screening of inner shells with increasing of inner electrons binding energies for metal ions. This effect can be observed by several experimental methods, in particular, chemical shift of inner atomic shell energy can be detected as a variation in core level binding energy (BE) in X-ray photoelectron spectroscopy (XPS) spectra. Both effects are generated by the redistribution of valence 
electrons and a correlation is expected between the metal-oxygen distance and the element core level $\mathrm{BE}$ variation. Such quantitative relations were observed in several studies carried out for different oxide chemical families [24-29]. So, it is of tremendous interest to relate the $\mathrm{Nb}-\mathrm{O}$ and $\mathrm{Ta}-\mathrm{O}$ bonding in niobates and tantalates with crystal structural parameters. The results presented would be valuable in XPS observation of these materials modified with doping or activation agents.

\section{ATOMIC NET MODEL}

Generally, atom distribution over crystal lattice space can be considered using different approaches [30]. Cation or anion polyhedra model is most popular to envisage the atomic coordination in crystal lattice of complex compound. This model was used for the preparation of Figures 1 and 2 illustrating crystal structure of representative niobates $\mathrm{LaNbO}_{4}$ and $\mathrm{LiNbO}_{3}$. Another approach has been proposed in several studies devoted to structural features evaluation of multicomponent crystals related to different chemical classes [31-35]. This model was successfully applied for the exploration of such challenging questions as crystal chemistry of mercury minerals, structural types of transition metal oxides and fluorides, epitaxial contacts of complex crystals [36-39].

Detailed analysis of crystal structure geometry made for known niobates and tantalates reveals presence of regular cation sublattices as a basis of crystal lattice. Such cation sublattices are found for various cation combination including small and light ( $\mathrm{Li}, \mathrm{Na}, \mathrm{Mg}$ ) and big and heavy (Mo $\mathrm{W}$, rare earth elements) atoms. On the geometry type these sublattices can be classified over three possible groups: 1) close to cubic face-centered ( $F-$ type $) ; 2)$ close to cubic bulk-centered ( $I-$ type); 3) hexagonal sublattices, $\mathrm{K}_{2} \mathrm{UF}_{6}$-type, formed by two intersecting hexagonal grids with distribution of cations on the different scale grids $[36,37,40]$. Previously, the structural parameters were defined for the cation sublattices observed for numerous niobates and tantalates related to wide structural types $[36,37,40]$. As an example, the structure of $\mathrm{LaNbO}_{4}$ is considered here. Cation space distribution in $\mathrm{LaNbO}_{4}$ is very similar to that of sheelite-type crystals. The unit cell of $\mathrm{LaNbO}_{4}$, in space group $I 2 / a, a=5.569 \AA, b=11.529 \AA, c=5.206 \AA, \beta=$ $94.09^{\circ}$, is formed by two cationic face-centered sublattices linked by a common face ortogonal to the $b$-axis [12]. Respectively, the parameters of cation $F$ - sublattice are $a_{\mathrm{k}}=$ 5.57, $b_{\mathrm{k}}=5.77, c_{\mathrm{k}}=5.21 \AA, \alpha_{\mathrm{k}}=\gamma_{\mathrm{k}}=90^{\circ}, \beta_{\mathrm{k}}=94.07^{\circ}$ [40].

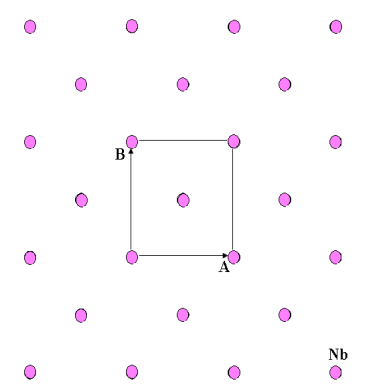

Fig. 3. Square net of niobium atoms in the crystallographic planes (024) of $\mathrm{LiNbO}_{3}$ structure $\left(a=5.142 \AA, b=5.487 \AA, \gamma=90.00^{\circ}\right)$.
A case of well-known trigonal $\mathrm{LiNbO}_{3}$ structure, in space group $R 3 c(a=5.14739, c=13.85614 \AA, Z=6)$ is evidently more complicated [13]. When the cation distribution was analyzed for the three crystallographic planes $(024),(\overline{2} 04)$ and $\left(\begin{array}{lll}2 & \overline{2} & 4\end{array}\right)$ linked by three-fold symmetry axis, the quazi-cubic cation $I$-sublattice was found with the parameters $a_{\mathrm{k}}=b_{\mathrm{k}}=c_{\mathrm{k}}=3.76 \AA, \alpha_{\mathrm{k}}=\beta_{\mathrm{k}}=\gamma_{\mathrm{k}}=86.28^{\circ}$. The square nets on two alternating (024) planes are formed in turn by niobium and lithium cations. The nets are shown in Figures 3 and 4 .

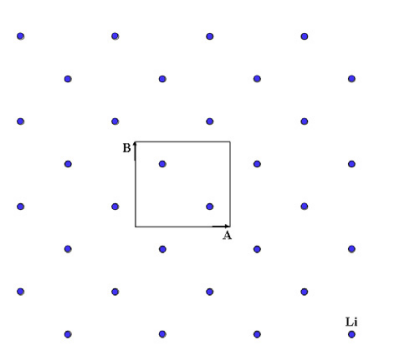

Fig. 4. Square net of lithium atoms in the crystallographic planes (024) of $\mathrm{LiNbO}_{3}$ structure $\left(a=5.142 \AA, b=5.487 \AA, \gamma=90.00^{\circ}\right)$.

These are the coordinate planes of $I$-type cation sublattice. Cation distributions shown in Figures 3 and 4 are confirmed by trigonal cation nets detected for crystallographic planes (104) and (110). These crystallographic planes are the closely-packed planes $\{110\}$ in the cubic $I$-sublattices. The cation distribution in the (104) crystallographic plane is shown in Fig. 5. When the crystal properties are analyzed in terms of the atom space distribution and atom-atom first-shell contacts, it is reasonable to conclude that the crystal state is controlled by specific ordering rules [30,40-42]. The distribution of heavy atoms, cations in niobates and tantalates, is most strictly limited by atomic ordering. The variations of interatomic distances appeared dominantly due to less strict ordering of light anions, oxygens in niobates and tantalates.

\section{NIOBATES}

The electronic parameters of niobates, which were evaluated with XPS up to now, are shown by points in Figure 6. Because of severe dielectric nature of $\mathrm{Nb}^{5+}$-niobates severe surface charging is typically observed during XPS measurements. On this reason the BE difference $\Delta(\mathrm{O}-\mathrm{Nb})=$ $\mathrm{BE}(\mathrm{O} 1 \mathrm{~s})-\mathrm{BE}\left(\mathrm{Nb} \mathrm{3d_{5/2 }}\right)$ was used as a key parameter to characterize average $\mathrm{Nb}-\mathrm{O}$ bonding. This difference parameter is evidently more reliable than using the absolute $\mathrm{BE}$ value of individual core levels which is typically used in bonding analysis. When $\mathrm{BE}(\mathrm{O} 1 \mathrm{~s})$ or $\mathrm{BE}\left(\mathrm{Nb} 3 \mathrm{~d}_{5 / 2}\right)$ parameters of the constituent element core levels are used for this purpose, they are usually calibrated in reference to the $\mathrm{C}$ 1s core level whose BE value may be different in different spectrometers.

The diagram shown in Figure 6 was partly presented in Ref. 24 previously and now the collection of the compounds is expanded by including additional experimental data measured with XPS for several new compounds and published in literature. General $\Delta(\mathrm{O}-\mathrm{Nb})$ has a tendency toincrease with increasing $L(\mathrm{Nb}-\mathrm{O})$, the average bond distance between $\mathrm{Nb}$ and $\mathrm{O}$. So, ionicity of the $\mathrm{Nb}-\mathrm{O}$ bonds is 


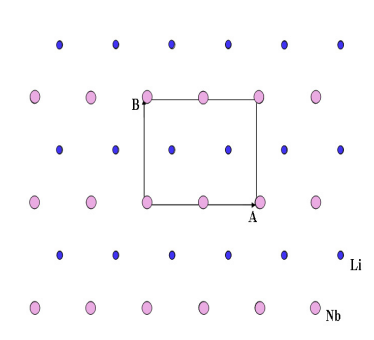

Fig. 5. Trigonal cation nets for $\mathrm{Nb}$ and $\mathrm{Li}$ in crystallographic plane (104) of $\mathrm{LiNbO}_{3}$ lattice $\left(\mathrm{A}=7.519 \AA, \mathrm{B}=5.487 \AA, \gamma=84.91^{\circ}\right)$.

Decreasing on increasing $L(\mathrm{Nb}-\mathrm{O})$. Upper level of $\Delta(\mathrm{O}-\mathrm{Nb})$ parameter is governed by a group of fergusonite-type rare-earth niobates. All the niobates, excepting $\mathrm{Mo}_{3} \mathrm{Nb}_{2} \mathrm{O}_{14}$ [44], are found to be over a range of $\Delta(\mathrm{O}-\mathrm{Nb})=322.8-323.6 \mathrm{eV}$ and $L(\mathrm{Nb}-\mathrm{O})=194-210 \mathrm{pm}$. So, high value $\Delta(\mathrm{O}-\mathrm{Nb})=323.8 \mathrm{eV}$ obtained for $\mathrm{Mo}_{3} \mathrm{Nb}_{2} \mathrm{O}_{14}$ seems to be overestimated presumably due to surface hydration during sample handling that shifts the $\mathrm{O} 1 \mathrm{~s}$ line to higher $\mathrm{BE}$ energy. Two presently known effective photocatalytic niobates for water splitting, $\mathrm{Sr}_{2} \mathrm{Nb}_{2} \mathrm{O}_{7}$ and $\mathrm{K}_{4} \mathrm{Nb}_{6} \mathrm{O}_{17}$, are characterized by intermediate level of $\Delta(\mathrm{O}-\mathrm{Nb})$ $\sim 323.1 \mathrm{eV}$. Several new prospective niobates have been discovered during recent years but electronic parameters of these oxides have not been measured with XPS [3,44-46].



Fig. 6. Dependence of $\Delta(\mathrm{O}-\mathrm{Nb})$ on $L(\mathrm{Nb}-\mathrm{O})$ in $\mathrm{Nb}^{5+}$-niobates.

\section{TANTALATES}

In Figure 7 the results of XPS measurements carried out for tantalates are shown. Similar to niobates, the BE difference $\Delta(\mathrm{O}-\mathrm{Ta})=\mathrm{BE}(\mathrm{O} 1 \mathrm{~s})-\mathrm{BE}\left(\mathrm{Ta} 4 \mathrm{f}_{7 / 2}\right)$ was used as a suitable parameter to characterize the average $\mathrm{Ta}-\mathrm{O}$ bonding in dielectric $\mathrm{Ta}^{5+}$-tantalates. The number of tantalates analyzed by XPS so far is very limited and further measurements are required in order to have a representative number of these

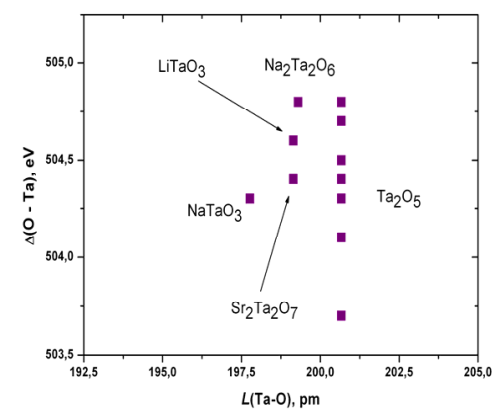

Fig. 7. Dependence of $\Delta(\mathrm{O}-\mathrm{Ta})$ on $L(\mathrm{Ta}-\mathrm{O})$ in $\mathrm{Ta}^{5+}$-tantalates.
Intriguing compounds. As to presently available XPS paramaters for tantalates, a great scattering of electronic parameters is reported for $\mathrm{Ta}_{2} \mathrm{O}_{5}$ in literature without any physical reason $[15,29]$. Evidently, new and more accurate XPS measurements with precise control of sample phase composition and surface chemical state are desirable for this widely used oxide. However, the position of very effective photocatalytic tantalate $\mathrm{Sr}_{2} \mathrm{Ta}_{2} \mathrm{O}_{7} \quad[29,47]$ is also at the middle value $\Delta(\mathrm{O}-\mathrm{Ta}) \sim 504.4 \mathrm{eV}$ similar to that evaluated for photocatalytic niobates. At room temperature the $\mathrm{Sr}_{2} \mathrm{Ta}_{2} \mathrm{O}_{7}$ crystal structure is orthorhombic, in space group $\mathrm{Cmcm}$ [48]. The unit cell is quite large, with $a=393.7, b=$ $2719.8, c=569.2 \mathrm{pm}$ and $Z=4$ [48]. The structure of $\mathrm{Sr}_{2} \mathrm{Ta}_{2} \mathrm{O}_{7}$ is formed by slabs (with a perovskite-type structure) parallel to the (010) planes. There are two types of Ta atoms, both in octahedral position, with similar Ta-O distances in the range of 187-216 and 189-207 pm respectively. There are also two types of $\mathrm{Sr}$ positions. $\mathrm{The} \operatorname{Sr}(1)$ atom, lying near the boundary of the slab and linking adjacent slabs, is surrounded by eight oxygens at a distance 247-327 pm away (not counting those bonding with more distant oxygen atoms). $\operatorname{The} \operatorname{Sr}(2)$ atom is positioned inside the slab and coordinated to twelve oxygen atoms with a $\mathrm{Sr}-\mathrm{O}$ distance in the range of 271-285 pm.

Many other photocatalytic tantalates are discovered over recent years and now this chemical oxide class is considered as the most promising for further search of new complex photocatalysts workable for water splitting $[3,47]$. Investigations of electronic structure of complex tantalates is expected to reveal factors governing the photocatalytic activity and physical properties of these compounds.

\section{CONCLUSIONS}

The present study has explored the relation between the structural and electronic parameters of niobates and tantalates with emphasis on the photo-catalytically active materials. An observation of structural features is made by comparison with atomic net model to see the general tendency in crystal lattice formation. The model is universal and can be used for the observation of crystal structure of multielement compounds. It has been shown that core level photoemission spectroscopy of complex oxides is an excellent method for the evaluation of bonding effects. Presently only a few photocatalytic niobates and tantalates have been accurately observed with XPS, and further accumulation of experimental results is beneficial in order to establish reliable correlations between the structural and electronic parameters, which will be helpful for the design of new effective catalytic materials. A set of chemically stable rare-earth-bearing perovskites $\mathrm{Ln}_{1 / 3} \mathrm{MO}_{3}$ would be considered for this purpose $[49,50]$.

\section{REFERENCES}

[1] V. V. Atuchin, C. C. Ziling, D. P. Shipilova, and N. F. Beizel, "Crystallographic, ferroelectric and optical properties of $\mathrm{TiO}_{2}$-doped $\mathrm{LiNbO}_{3}$ crystals," Ferroelectrics, vol. 100, pp. 261-269, 1989.

[2] I. Savatinova, C. C. Ziling, and V. V. Atuchin, "Metastable states in proton exchanged layers $\mathrm{H}: \mathrm{LiMO}_{3}(\mathrm{M}=\mathrm{Nb}, \mathrm{Ta})$," Opt. Mater., vol. 12, pp. 157-162, 1999

[3] F. E. Osterloh, "Inorganic materials as catalysts for photochemical splitting of water," Chem. Mater., vol. 20, pp. 35-54, 2008. 
[4] Feng Chen, "Photonic guiding structures in lithium niobate crystals produced by energetic ion beams," J. Appl. Phys., vol. 106, pp. 081101, 2009.

[5] Ricardo López-Medina, J. L. G. Fierro, M. Olga Guerrero-Pérez, and Miguel A. Bañares, "Nanoscale rutile active phase in $\mathrm{Mo}-\mathrm{V}-\mathrm{Nb}-\mathrm{O}$ supported catalysts for the oxidation of propane to acrylic acid," Appl. Catal. A: General, vol. 375, pp. 55-62, 2010.

[6] Kyooho Jung, Yongmin Kim, Woong Jung, Hyunsik Im, Baeho Park, Jinpyo Hong, Jiyeong Lee, Jongku Park, and Jeon-Kook Lee, "Electrically induced conducting nanochannels in an amorphous resistive switching niobium oxide films," Appl. Phys. Lett., vol. 97, pp. 233509, 2010.

[7] In-Sun Cho, Dong Wook Kim, Tae Hoon Noh, Sangwook Lee, Dong Kyun Yim, and Kug Sun Hong, "Preparation of N-doped $\mathrm{CaNb}_{2} \mathrm{O}_{6}$ nanoplates with ellipsoid-like morphology and their photocatalytic activities under visible-light irradiation," J. Nanosci. Nanotech., vol. 10, pp. 1196-1202, 2010.

[8] P. Shiv Halasyamani and Kenneth R. Poeppelmeier, "Noncentrosymmetric oxides," Chem. Mater., vol. 10, pp. 2753-2769, 1998.

[9] V. V. Atuchin, B. I. Kidyarov, and N. V. Pervukhina, "Phenomenological modeling and design of new acentric crystals for optoelectronics," Comput. Mater. Sci., vol. 30, pp.411-418, 2004.

[10] A. S. Korotkov and V. V. Atuchin, "Distribution, structures and nonlinear properties of noncentrosymmetric niobates and tantalates," $J$. Solid State Chem., vol. 179, pp. 1177-1182, 2006.

[11] B. I. Kidyarov and V. V. Atuchin, "Interrelationship of micro- and macrostructure with nonlinear optical properties of simple and binary acentric niobate crystals," Ferroelectrics, vol. 397, pp. 159-168, 2010.

[12] V. K. Trunov and L. N. Kinzhibalo, "The change of structures of $\mathrm{LnNbO}_{4}$ in lanthanoid series," Doklady Akademii Nauk SSSR, vol. 263, pp. $348-351,1982$.

[13] S. C. Abrahams and P. Marsh, "Defect structure dependence on composition in lithium niobate," Acta Cryst. B, vol. 42, pp. 61-68, 1986.

[14] Victor V. Atuchin, Hirotoshi Nagata, Ke-ichi Kawamura, Kaoru Higuma, Junichiro Ichikawa, Lev D. Pokrovsky, Hiroshi Takai, and Hideo Hosono, "Structure and refractive indices of proton-implanted $\mathrm{LiNbO}_{3}$," Jpn. J. Appl. Phys., vol. 39, pp. 2653-2656, 2000.

[15] V. A. Shvets, V. Sh. Aliev, D. V. Gritsenko, S. S. Shaimeev, E. V. Fedosenko, S. V. Rykhlitski, V. V. Atuchin, V. A. Gritsenko, V. M. Tapilin, and $\mathrm{H}$. Wong, "Electronic structure and charge transport properties of amorphous $\mathrm{Ta}_{2} \mathrm{O}_{5}$ films," J. Non-Cryst. Solids, vol. 354 pp. 3025-3033, 2008

[16] I. S. Steinberg, I. E. Kalabin, and P. E. Tverdokhleb, "Two-photon induced photorefraction in undoped lithium tantalate crystals with different compositions,“ Appl. Phys. B, vol. 95, pp. 407-411, 2009.

[17] V. V. Atuchin and T. Khasanov, "High-accuracy contactless method for determination of chemical composition of lithium niobate crystals by their birefringence," Optics Spectr., vol. 107, pp. 212-216, 2009.

[18] R. M. Taziev, "SAW excitation properties on YX-cut of CNGS and SNGS single crystals," IEEE Trans. Ultrasonics Ferroelect. Freq. Control, vol. 57, pp. 2370-2371, 2010.

[19] V. V. Atuchin, V. G. Kesler, N. Yu. Maklakova, L. D. Pokrovsky, and V. N. Semenenko, "Study of $\mathrm{KTiOPO}_{4}$ surface by X-ray photoelectron spectroscopy and reflection high-energy electron diffraction," Surf. Interface Anal., vol. 34, pp. 320-323, 2002.

[20] V. V. Atuchin, T. I. Grigorieva, I. E. Kalabin, V. G. Kesler, L. D. Pokrovsky, and D. I. Shevtsov, "Comparative analysis of electronic structure of Ti:LiNbO 3 and $\mathrm{LiNbO}_{3}$ surfaces,“ J. Cryst. Growth, vol. 275, pp. e1603-e1607, 2005.

[21] Lei Wang and Bing-Xi Xiang, "Planar waveguides in magnesium doped stoichiometric $\mathrm{LiNbO}_{3}$ crystals formed by $\mathrm{MeV}$ oxygen ion implantations," Nucl. Instrum. Methods Phys. Res. B, (2011) doi: 10.1016/j.nimb.2011.01.046.

[22] V. V. Atuchin, C. C. Ziling, I. Savatinova, M. N. Armanise, and V. M. N. Passaro, "Waveguide formation mechanism generated by double doping in ferroelectric crystals," J. Appl. Phys., vol. 78, pp. 6936-6939, 1995.

[23] Chao He, Xiuzhi Li, Zujian Wang, Xifa Long, Shaoyu Mao, and Zuo-Guang Ye, "Preparation and characterization of new $\mathrm{Pb}\left(\mathrm{Yb}_{1 / 2} \mathrm{Nb}_{1 / 2}\right) \mathrm{O}_{3}-\mathrm{Pb}\left(\mathrm{Mg}_{1 / 3} \mathrm{Nb}_{2 / 3}\right) \mathrm{O}_{3}-\mathrm{PbTiO}_{3}$ ternary piezo/ferroelectric crystals," Chem. Mater., vol. 22, pp. 5588-5592, 2010.

[24] V. V. Atuchin, I. E. Kalabin, V. G. Kesler, and N. V. Pervukhina, "Nb $3 \mathrm{~d}$ and $\mathrm{O} 1 \mathrm{~s}$ core levels and chemical bonding in niobates," J. Elect. Spectr. Rel. Phenom., vol. 142, pp. 129-134, 2005.

[25] Victor V. Atuchin, Valery G. Kesler, Natalia V. Pervukhina, and Zhaoming Zhang, "Ti 2 p and $\mathrm{O}$ 1s core levels and chemical bonding in titanium-bearing oxides," J. Elect. Spectr. Rel. Phenom., vol. 152, pp. 18-24, 2006

[26] V. V. Atuchin, V. G. Kesler, and N. V. Pervukhina, "Electronic and structural parameters of phosphorus-oxygen bonds in inorganic phosphate crystals," Surf. Rev. Lett., vol. 15, pp. 391-399, 2008.

[27] V. V. Atuchin, J.-C. Grivel, A. S. Korotkov, and Zhaoming Zhang, "Electronic parameters of $\mathrm{Sr}_{2} \mathrm{Nb}_{2} \mathrm{O}_{7}$ and chemical bonding," J. Solid State Chem., vol. 181, pp. 1285-1291, 2008.

[28] V. V. Atuchin, V. G. Kesler, V. K. Sapozhnikov, and V. N. Yakovenchuk, "X-ray photoelectron spectrometry and binding energies of $\mathrm{Be} 1 \mathrm{~s}$ and $\mathrm{O}$ 1s core levels in clinobarylite, $\mathrm{BaBe}_{2} \mathrm{Si}_{2} \mathrm{O}_{7}$, from Khibiny massif, Kola peninsula," Mater. Charact., vol. 59, pp. 1329-1334, 2008.

[29] V. V. Atuchin, J.-C. Grivel, and Zhaoming Zhang, "Core level photoemission spectroscopy and chemical bonding in $\mathrm{Sr}_{2} \mathrm{Ta}_{2} \mathrm{O}_{7}$," Chem. Phys., vol. 360, pp. 74-78, 2009.

[30] S. V. Borisov, "Geometric laws in inorganic chemistry," Cryst. Reports, vol. 45, pp. 709-713, 2000.

[31] N. A. Bliznyuk and S. V. Borisov, "Calculation of the similarity index of crystal structures - algorithm, program and examples," J. Struct. Chem., vol. 32, pp. 84-89, 1991.

[32] N. A. Bliznyuk and S. V. Borisov, "Development of methods for geometric analysis of inorganic structures," J. Struct. Chem., vol. 33, pp. 284-304, 1992.

[33] S. V. Borisov, "Crystalline state," J. Struct. Chem., vol. 33, pp. 871-877, 1992.

[34] S. V. Borisov, N. A. Bliznyuk, E. S. Kuklina, N. V. Podberezskaya, and T. S. Yudanova, "Classification of heavy-metal fluorides - fluorides with square-rhombic cation net of the 3(2)434 type," J. Struct. Chem., vol. 34, pp. 755-763, 1993.

[35] S. V. Borisov, N. V. Pervukhina, and S. A. Magarill, "Atomic sublattices: Problems of indexing powder patterns, structural model determination," J. Struct. Chem., vol. 47, pp. 875-880, 2006.

[36] S. V. Borisov, E. N. Ipatova, and E. S. Kuklina, "Basic structural types of binary niobates and tantalates with $1 / 3$-stoichiometry of cations variants of cation arrangements in planar nets," J. Struct. Chem., vol. 36, pp. 112-120, 1995.

[37] S. V. Borisov, "Comparative crystal chemistry of heavy metal fluorides and complex niobates and tantalates in terms of a new crystalline state concept," J. Struct. Chem., vol. 37, pp. 773-779, 1996.

[38] N. V. Pervukhina, G. V. Romanenko, S. V. Borisov, S. A. Magarill, and N. A. Palchik, "Crystal chemistry of mercury(I) and mercury(I, II) minerals," J. Struct. Chem., vol. 40, pp. 461-476, 1999.

[39] V. V. Atuchin, S. V. Borisov, S. A. Magarill, and N. V. Pervukhina, "Crystal structural premises to epitaxial contacts for a series of mercury-containing compounds," J. Cryst. Growth, vol. 318, pp. 1125-1128, 2011.

[40] S. V. Borisov, E. N. Ipatova, and E. S. Kuklina, "Main structural types of cation matrices of binary niobates and tantalates with the cation ratio 1:2," J. Struct. Chem., vol. 37, pp. 278-287, 1996.

[41] N. V. Pervukhina, S. V. Borisov, S. A. Magarill, D. Y. Naumov, V. I. Vasil'evz, "The crystal structure of kelyanite, $(\mathrm{Hg}-2)_{6}\left(\mathrm{SbO}_{6}\right) \mathrm{BrCl}_{2}$," Am. Miner., vol. 93, pp. 1666-1669, 2008.

[42] S. V. Borisov, S. A. Magarill, N. V. Pervukhina, "Characteristic features of crystal chemistry of natural mercury-containing sulfides and sulfosalts," J. Struct. Chem., vol. 50, pp. 853-860, 2009

[43] P. Afanasiev, "Structure and properties of $\mathrm{Mo}_{3} \mathrm{Nb}_{2} \mathrm{O}_{14}$," J. Phys. Chem. B, vol. 109, pp. 18293-18300, 2009.

[44] Z. M. Wang, D. R. Yuan, Y. Sh. Yin, and X. Wang, "Optical and dielectric properties of $\mathrm{Sr}_{3} \mathrm{NbGa}_{3} \mathrm{Si}_{2} \mathrm{O}_{14}$ crystals," J. Alloys Compd., vol. 425, pp. 264-267, 2006.

[45] Masatomo Yashima, Shota Matsuyama, Rikiya Itoh, Kenji Tsuda, and Desheng Fu, "Structure of ferroelectric silver niobate $\mathrm{AgNbO}_{3}$," Chem Mater., vol. 23, pp. 1643-1645, 2011

[46] Nahum Masó, David I. Woodward, Pam A. Thomas, Alejandro Várez, and Anthony R. West, "Structural characterization of ferroelectric $\mathrm{Ag}_{2} \mathrm{Nb}_{4} \mathrm{O}_{11}$ and dielectric $\mathrm{Ag}_{2} \mathrm{Ta}_{4} \mathrm{O}_{11}$," J. Mater. Chem., vol. 21, pp. 2715-2722, 2011.

[47] Akihiko Kudo, Hideki Kato, and Seira Nakagawa, "Water splitting into $\mathrm{H}_{2}$ and $\mathrm{O}_{2}$ on new $\mathrm{Sr}_{2} \mathrm{M}_{2} \mathrm{O}_{7}(\mathrm{M}=\mathrm{Nb}, \mathrm{Ta})$ photocatalysts with layered perovskite structures: Factors affecting the photocatalytic activity," $J$. Phys. Chem. B, vol. 104, pp. 571-575, 2000.

[48] N. Ishizawa, F. Marumo, T. Kawamura, and M. Kimura, "Compounds with perovskite-type slabs. II. The crystal structure of $\mathrm{Sr}_{2} \mathrm{Ta}_{2} \mathrm{O}_{7}$," Acta Cryst. B, vol. 32, pp. 2564-2566, 1976.

[49] Z. M. Zhang, C. J. Howard, B. J. Kennedy, K. S. Knight, and Q. D. Zhou, "Crystal structure of $\mathrm{Ln}_{1 / 3} \mathrm{NbO}_{3}(\mathrm{Ln}=\mathrm{Nd}, \mathrm{Pr})$ and phase 
transition in $\mathrm{Nd}_{1 / 3} \mathrm{NbO}_{3}$, "J. Solid State Chem., vol. 180, pp.1846-1851, 2007.

[50] Q. D. Zhou, P. J. Saines, N. Sharma, J. Ting, B. J. Kennedy, Z. M. Zhang, R. L. Withers, and K. S. Wallwork, "Crystal structures and phase transitions in A-site deficient perovskites $\mathrm{Ln}_{1 / 3} \mathrm{TaO}_{3}$, " Chem. Mater., vol. 20, pp. 6666-6676, 2008.

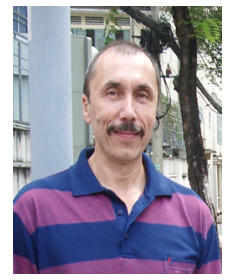

Victor V. Atuchin,was born in Prokopievsk / Russia on August, 1957. He received the diploma degree in radiophysics from the Tomsk State University, Tomsk/Russia in 1979 and the Ph.D. degree in solid state physics from the Institute of Semiconductor Physics of SB of RAS, Novosibirsk/Russia, in 1993. In 1980, he joined the Institute of Semiconductor Physics as an Engineer of Electronics, and as Head of Laboratory of Optical Materials and Structures in July 2002. Since 1980, his principal research interests have been in the fields of solid state physics, and materials science. His interests include fabrication and characterization of thin films, surface science and chemistry of oxide crystals. He is the author or coauthor of 189 publications in refereed journals. Prof. Atuchin is a member of IUCr.

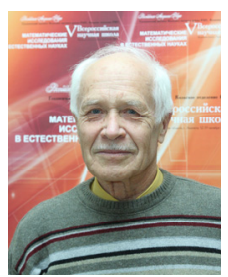

Stanislav V. Borisov, was born in July 1930. He received her B.S. degree in physics and mathematics from Gorky State University (Gorky, USSR) in 1953, Ph.D. degree in crystallography and crystal physics from the Institute of Crystallography, RAS (Moscow, Russia) in 1964 and D.Sc. in crystallography and crystal physics from the Institute of Crystallography, RAS (Moscow, Russia) in 1974.

Presently, he is working as Principal Research Scientist in Institute of Inorganic Chemistry, SB RAS (Novosibirsk, Russia). Over many years, his research activities cover wide range of topics including crystallography, X-ray structural analysis, crystal properties, mineralogy and inorganic chemistry. He has published more than 200 refereed research articles in refereed journals and 5 monographs.

Prof. Borisov is awarded by Fedorov's Prize of Russian Academy of Science and is a member of IUCr.

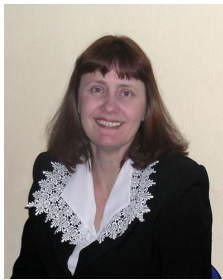

Natalia V. Pervukhina,was born in Novokuznetsk/Russia on February, 1955. She received the diploma of chemist from the Novosibirsk State University in 1977 and the Ph.D. degree in inorganic chemistry from the Institute of Inorganic Chemistry, SB of RAS, Novosibirsk, Russia, in 1990.

In 1977, she joined the Institute of Inorganic Chemistry, an Siberian Branch (SB), Russian Academy of Sciences (RAS). Since 1980, her principal research interests were concerned with X-ray structure analysis and crystal chemistry of inorganic and complex compounds. She is the author and coauthor of 200 publications in refereed journals.

Prof. Pervukhina is a member of IUCr.

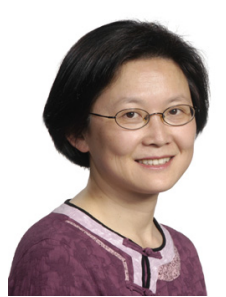

Zhaoming Zhang, was born in Shanghai, China in September 1962. She received her B.S. degree in physics from Fudan University (Shanghai) in 1984, and her Ph.D. in applied physics from Yale University (New Haven, Connecticut, USA) in 1993 She joined the research staff at the Australian Nuclear Science and Technology Organisation (ANSTO) in Sydney, Australia in 1993, where she remains today as a Principal Research Scientist in the Institute of Materials Engineering. Over the past 20 years, she has conducted a wide range of research activities, ranging from fundamental studies in surface science and bulk crystallography to more applied topics such as the development of nuclear waste form materials. She has published more than 70 refereed research articles in international journals and conference proceedings. 